\title{
CORONARY-CORONARY BYPASS GRAFT: AN ARTERIAL CONDUIT-SPARING PROCEDURE
}

R. Nottin, MD

J. M. Grinda, MD

S. Anidjar, MD

T. Folliguet, MD

M. Detroux, MD

Sponsor: C. Planché, MD
From May 1989 to December 1995, 143 patients underwent myocardial revascularization with one (138 patients) or two (five patients) coronarycoronary bypass grafts in addition to other bypass grafts, for a total of 463 distal anastomoses (mean $3.2 \pm \mathbf{0 . 6}$ per patient). Coronary-coronary bypass grafts were chosen for the following reasons: arterial conduit-sparing procedure, inadequate length for in situ graft, calcified ascending aorta, and stenosed or occluded subclavian arteries. One hundred eleven arterial grafts $(75 \%)$ were used: 85 right internal thoracic arteries, 18 left internal thoracic arteries, and eight radial arteries. Saphenous vein grafts were used in 37 cases (25\%, mostly in our early experience). Coronary-coronary bypass grafts were performed on the right coronary artery in 134 cases $(90.5 \%)$, on the circumflex artery in five cases $(3.3 \%)$, on the left anterior descending coronary artery in four cases $(2.7 \%)$, and between two different coronary arteries in five cases $(3.3 \%)$. Three patients (2\%) died of myocardial infarction. Early postoperative angiography showed a patency rate of 98.6\% (72/73). During the mean follow-up of $34.6 \pm 20.8$ months, two patients died and two underwent reoperation. Results of exercise testing were normal at 2 months in $97 \%$ of patients (90/92), at 1 year in $96 \%$ $(81 / 84)$, and at 3 years in $93 \%(30 / 32)$. In conclusion, the coronary-coronary bypass graft provides good results with a variety of conduits and allows the expanded use of arterial grafts, particularly the internal thoracic artery. This can lead to a sparing of arterial conduit and allow complex myocardial revascularization with a liberal use of internal thoracic arteries. ( $J$ Thorac Cardiovasc Surg 1996;112:1223-30)
T he internal thoracic artery (ITA) is unquestionably the best coronary graft. ${ }^{1}$ Consequently, the current trend is to use ITA as much as possible in coronary artery operations. Nevertheless, the use of both ITAs still remains limited in cases of multiple bypasses. The inadequate length of the right ITA to reach the posterolateral wall of the myocardium and the disappointing patency rates of aortic free arterial graft anastomoses along, with the increased risk

From the Centre Chirurgical Marie Lannelongue, Le PlessisRobinson, France.

Read at the Seventy-sixth Annual Meeting of The American Association for Thoracic Surgery, San Diego, Calif., April 28-May 1, 1996.

Received for publication May 6, 1996; revisions requested May 30, 1996; revisions received June 24, 1996; accepted for publication July 10, 1996.

Address for reprints: R. Nottin, MD, Centre Chirurgical Marie Lannelongue, 133, Ave. de la Résistance, 92350 Le PlessisRobinson, France.

Copyright (C) 1996 by Mosby-Year Book, Inc.

$0022-5223 / 96 \$ 5.00+0 \quad \mathbf{1 2 / 6 / 7 6 3 3 8}$ of sternal wound complication, have limited right ITA harvesting. Because of these limitations, we consider coronary-coronary bypass grafts (CCBG) an interesting additive technique when used in the same way as $Y$ grafts or gastroepiploic artery grafts. Proximal and distal anastomoses can be achieved either between two segments of the same coronary artery or between two different coronary arteries. This practice of using shorter grafts allows increased use of one arterial graft, particularly of the right ITA, for revascularization of the most distal branches of the coronary arteries. To our knowledge, this study reports the largest series of CCBGs with midterm follow-up to date.

\section{Patients and methods}

Population. From May 1989 to December 1995, 143 patients of 1261 patients operated on for myocardial revascularization $(11.3 \%)$ had 148 CCBGs placed. The preoperative characteristics of these patients are summarized in Table I. One hundred one patients had threevessel disease $(70.6 \%)$ and 21 patients also had significant stenosis of the left main coronary artery $(14.7 \%)$. The left 


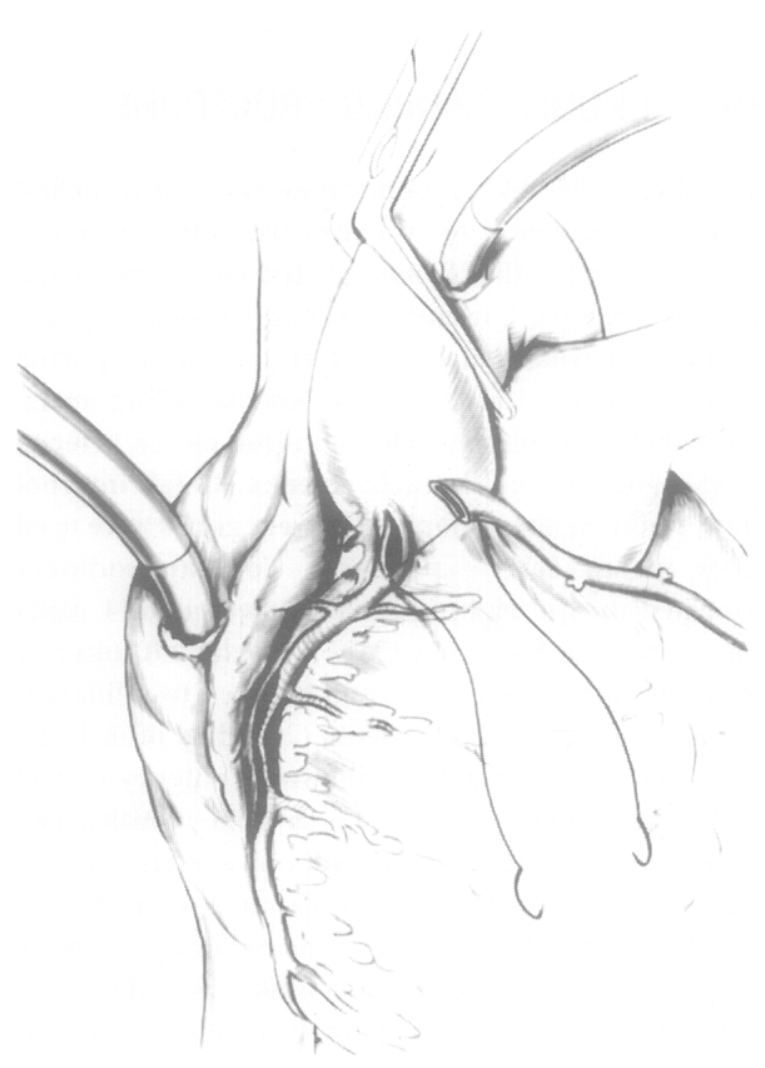

Fig. 1. Proximal anastomosis of CCBG on origin of RCA.

Table I. Patient characteristics

\begin{tabular}{|c|c|c|}
\hline & No. & $\begin{array}{c}\% \\
(n=143)\end{array}$ \\
\hline Age (yx) & $36-84(61)^{*}$ & \\
\hline Female & 26 & 18.2 \\
\hline Hyperlipidemia & 70 & 49 \\
\hline Diabetes mellitus & 27 & 18.8 \\
\hline Respiratory disease & 5 & 3.5 \\
\hline Obesity & 30 & 21 \\
\hline Previous myocardial infarction & 90 & 63 \\
\hline Unstable angina & 33 & 23 \\
\hline Emergency operation & 9 & 6.3 \\
\hline $\mathrm{LVEF}<0.3$ & 9 & 6.3 \\
\hline CABG reoperation & 4 & 2.8 \\
\hline
\end{tabular}

$L V E F$, Left ventricular ejection fraction; $C A B G$, coronary artery bypass grafting.

*Range with mean in parentheses.

ventricular ejection fraction was less than $49 \%$ in 43 patients $(30 \%)$ and less than $30 \%$ in nine patients $(6.3 \%)$.

Operative technique. A midline sternotomy was used. The arterial grafts were harvested skeletonized. All collateral branches were secured with metallic clips, and
Table II. Operative data

\begin{tabular}{lc}
\hline Total distal anastomoses & 462 \\
Mean no. of distal anastomoses per patient & $3.23 \pm 0.67$ \\
Sequential anastomoses & 82 \\
Y grafts & 65 \\
CCBGs & 148 \\
Saphenous graft & 37 \\
Arterial graft & 111 \\
$\quad$ Right ITA & 85 \\
$\quad$ Left ITA & 18 \\
$\quad$ Radial artery & 8 \\
No. patients with arterial grafts only & 94 \\
Cardiopulmonary bypass time (min) & $130 \pm 43$ \\
Aortic crossclamp time (min) & $83 \pm 27$ \\
\hline
\end{tabular}

grafts were divided after heparinization. When used in situ, ITA was clipped distally and wrapped with a papaverine and dipyridamole-soaked sponge. Arterial free grafts and venous grafts were preserved in a blood solution with heparin papaverine and dipyridamole.

Cardiopulmonary bypass with moderate hemodilution was established between a two-stage venous cannula and an arterial cannula. Myocardial protection was accomplished with a cold cardioplegic solution delivered through the aortic root and repeated about every 30 minutes. Retrograde coronary sinus cardioplegic administration was used in patients with incompetent aortic valves or severe left main coronary artery stenosis; it was also used for reoperations.

Anastomoses were performed with a continuous 8-0 polypropylene suture under optical magnification. Proximal implantation of CCBGs was performed in 137 of 148 cases $(92.6 \%)$ on the origin of the right coronary artery (RCA; Fig. 1), with care to avoid trauma to the collateral vessels arising at this level (the conal artery and the sinus node artery). A wide parallel end-to-side anastomosis was performed, the length of the graft was measured during injection of cardioplegic solution through the aortic root, and the distal anastomosis was then performed.

Operative data. A total of 234 arterial grafts (136 left ITAs, 84 right ITAs, six inferior epigastric arteries, and eight radial arteries) were used in association with 64 saphenous vein grafts to revascularize a total of 462 coronary arteries with an average of $3.23 \pm 0.67$ (range 2 to 7 ) distal anastomoses per patient. All anastomosis, including proximal anastomosis of CCBGs and Y grafts, were performed with aortic crossclamping. The general characteristics of these procedures are summarized in Table II. In five cases, two different CCBGs were constructed. Sequential anastomoses on CCBGs were performed in six cases. The sites of proximal and distal implantation of the CCBGs and the types of graft are listed in Table III. Myocardial revascularization was performed exclusively with arterial grafts in 94 cases $(65.7 \%)$. The ITA was divided into two segments, either one CCBG and one Y graft (41/143, 28.7\%; Fig. 2), or two CCBGs $(3 / 143,2 \%)$, one CCBG with the proximal part of the ITA remaining in situ (11/143, 7.7\%; Fig. 3), or sequential CCBGs $(7 / 143,4.9 \%)$. 


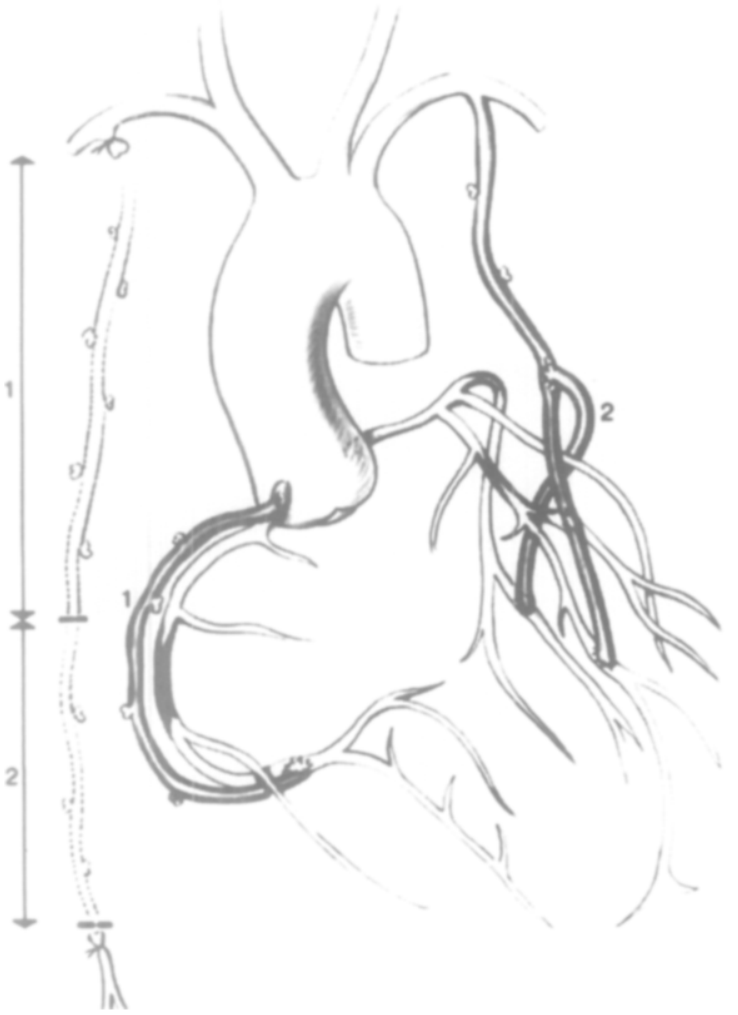

Fig. 2. CCBG with proximal part of right ITA (1) and one $Y$ graft with distal part of right ITA (2) anastomosed to two left ITAs.

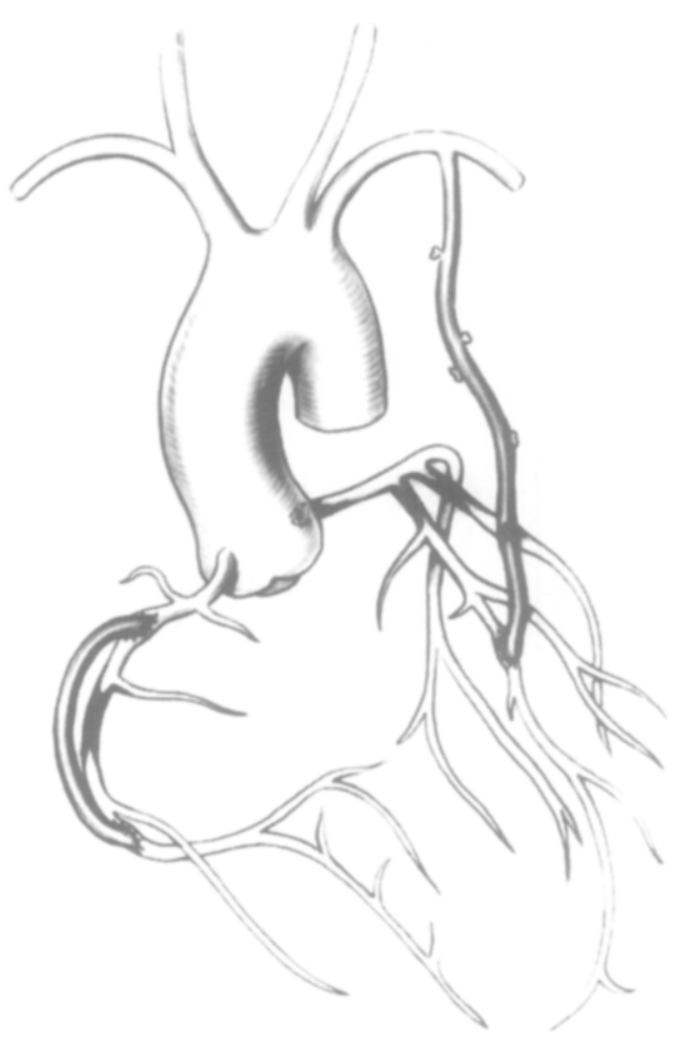

Fig. 3. CCBG on RCA with distal part of left ITA. Proximal in situ left ITA revascularized LAD and marginal arteries.

Table III. Types of CCBGs and grafts used

\begin{tabular}{|c|c|c|c|c|c|}
\hline & $R I T A$ & $L I T A$ & $S V G$ & $R A$ & Total \\
\hline $\mathrm{RCA}$ to $\mathrm{RCA}$ & 79 & 13 & 35 & 7 & 134 \\
\hline $\mathrm{RCA}$ to $\mathrm{LAD}$ & - & 3 & - & - & 3 \\
\hline $\mathrm{LAD}$ to $\mathrm{LAD}$ & 1 & 2 & 1 & - & 4 \\
\hline $\mathrm{CXA}$ to $\mathrm{CXA}$ & 4 & 0 & 1 & - & 5 \\
\hline LAD to DIAG to OM & 1 & - & - & 1 & 2 \\
\hline Total & 85 & 18 & 37 & 8 & 148 \\
\hline
\end{tabular}

RITA, Right ITA; LITA, left ITA; $S V G$, saphenous vein graft; $R A$, radial artery; $D L A G$, diagonal artery; $O M$, obtuse marginal artery.

Assessment criteria. Angiography was performed before discharge if the patient consented. Postoperative functional results were evaluated within the first 3 postoperative months on the basis of exercise testing. Exercise testing was repeated, when possible, after postoperative years 1 and 3 . Follow-up information was collected yearly or more frequently as necessary through direct patient contact, from the patient's personal physician, from responses to mailed questionnaires, or by telephone interview with surviving patients or family members.

\section{Results}

Operative mortality. Three patients $(2 \%)$ died on postoperative day 1 of myocardial infarction.
One patient had a saphenous CCBG on the RCA; the other two had CCBGs on the RCA performed with a free segment of left ITA.

Nonfatal postoperative complications. Nonfatal postoperative complications were low cardiac output (three patients), intraaortic balloon counterpulsation (one patient), ventilatory support longer than 48 hours (seven patients), and reoperations for hemostasis (four patients), for pericardial effusion (two patients), for sternal disjunction (two patients), for mediastinitis (three patients), for graft stenosis detected by early angiogram (one patient), and for gastric hemorrhage (one patient). 

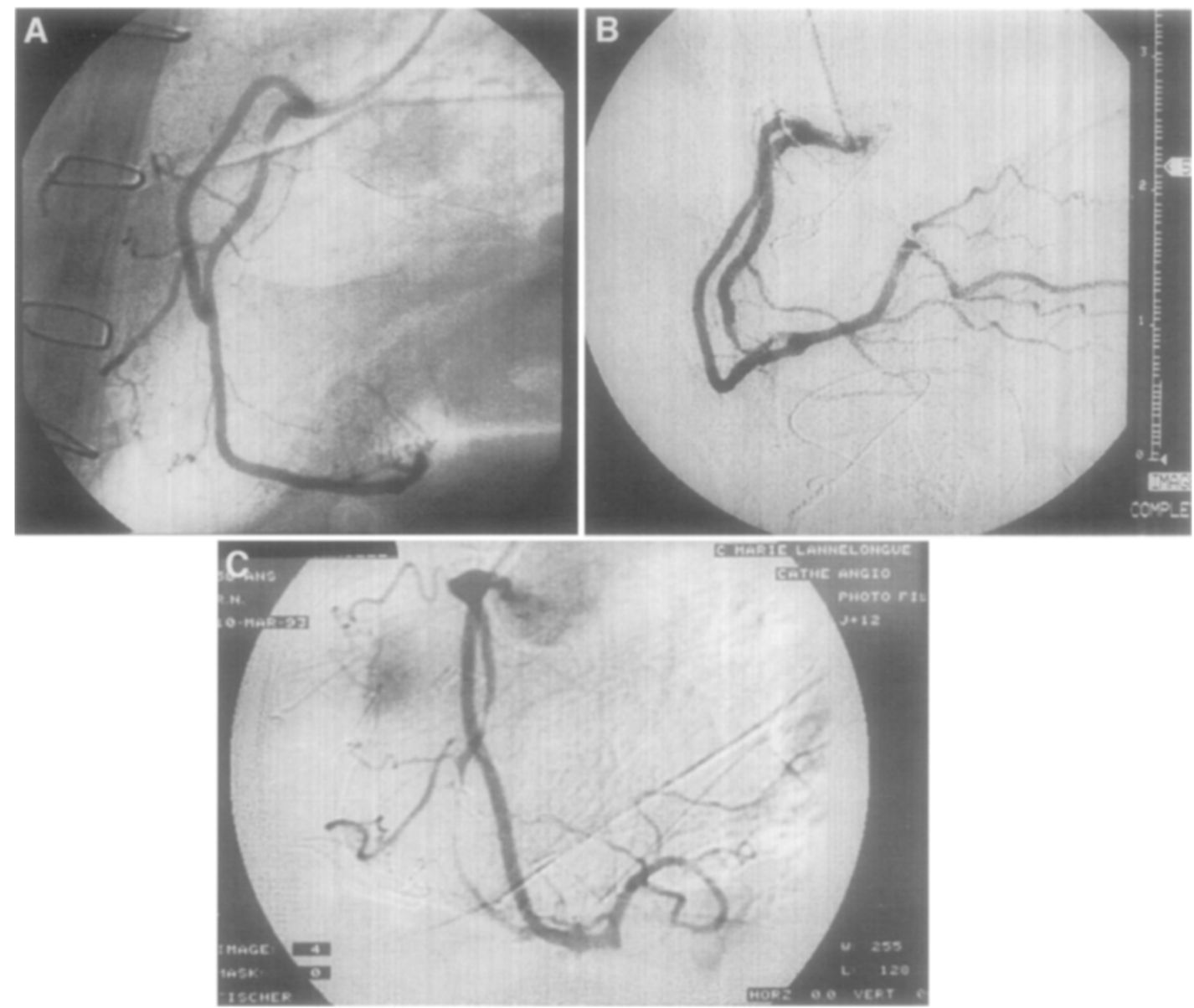

Fig. 4. Postoperative angiograms. A, Short CCBG on RCA. B, C, Long CCBGs on RCA.

Early graft patency. Seventy of 140 patients $(50 \%)$ consented to undergo coronary angiography during the first postoperative month (Fig. 4). A total of 73 CCBGs were controlled, with a patency rate of $98.6 \%(72 / 73)$. One arterial CCBG was occluded but the patient had no clinical symptoms. This patient had a right CCBG performed on an occluded RCA, with poor distal runoff and a preoperative posteroinferior myocardial infarction. All of the sequential anastomoses and all of the $Y$ anastomoses were patent. In two cases, however, a severe stenosis not relieved by in situ instillation of vasodilators was observed on an inferior epigastric artery grafted as a $\mathrm{Y}$ between the left ITA and circumflex artery (CXA) branch. Also, one severe anastomotic stenosis was noted between a venous graft and CXA branch. The patient with graft stenosis, as previously noted, had a satisfactory CCBG but had proximal stenosis of the left ITA graft that necessitated repair of the proximal mammary pedicle.

Early postoperative exercise testing. Ninety-two patients $(65.7 \%)$ of the 140 early survivors underwent exercise testing between postoperative months 1 and 3 . Electric abnormalities were found in two patients $(2.2 \%)$.

Late follow-up. Mean postoperative follow-up was $34.6 \pm 20.8$ months (range 3 to 82 months). No patients were unavailable for follow up.

Two patients $(2 / 140,1.4 \%)$ died. One patient with initial normal results of coronary angiography later had a mycotic aneurysm of the ascending aorta and died 5 months after operation. A 74-year-old woman who never underwent either postoperative coronary angiography or postoperative stress testing died suddenly 16 months after operation. This patient 
was known at the time of operation to have a nonsignificant aortic stenosis.

During the follow-up period, no myocardial infarctions were noted in any patient. Ten patients $(10 / 138$, $7.2 \%$ ) had recurrent angina pectoris. All 10 underwent coronary angiography. Two patients underwent reoperation. One was found to have an occlusion of an arterial CCBG on RCA and a de novo stenosis on the left anterior descending coronary artery (LAD); in the other patient with an arterial CCBG on RCA, a stenosis appeared distally on the RCA. Eight patients underwent percutaneous transluminal coronary angioplasty. One patient with proximal stenosis of a CCBG on RCA had unsuccessful dilatation, but adjustment of medical treatment provided relief of symptoms. Two patients with distal coronary stenoses had successful dilation through the CCBG. Five patients with wellfunctioning CCBGs underwent percutaneous transluminal coronary angioplasty on ungrafted coronary arteries (three patients) and on marginal artery distal to stenosed $\mathrm{Y}$ inferior epigastric artery graft (two patients).

One hundred twenty-eight patients (128/138, $92.7 \%$ ) were free of ischemic symptoms. At 1 year of follow-up, $68 \%$ of patients (81/119) underwent exercise testing, with abnormal results in three cases $(3 / 81,3.7 \%)$. At 3 years of follow-up, exercise testing was completed by 32 of the 66 patients (48\%), with abnormal results in one case. Ten patients underwent, between 12 and 72 months after operation, angiography that showed a well-functioning CCBG in all cases.

\section{Discussion}

In the early days of coronary surgery, resection of coronary segments and termino-terminal interposition of saphenous vein grafts were reported. ${ }^{2}$ In 1987, CCBG was revisited by Biglioli and colleagues. ${ }^{3}$ In $\mathrm{CCBG}$, proximal and distal anastomoses are performed between two segments of the same coronary artery or between two different coronary arteries. A normal proximal coronary artery is a prerequisite for this technique to provide adequate distal flow. The most usual site of proximal implantation for CCBG in this series, as for others, ${ }^{3-5}$ was the origin of the RCA $(92.6 \%)$. The initial segment of the RCA was used preferentially when the ostium and the first segment of RCA were often free of atherosclerosis and when adequate diameter and thickness of this vessel allowed a satisfactory congruence of the anastomosis with the graft. Initially, we considered complete occlusion of

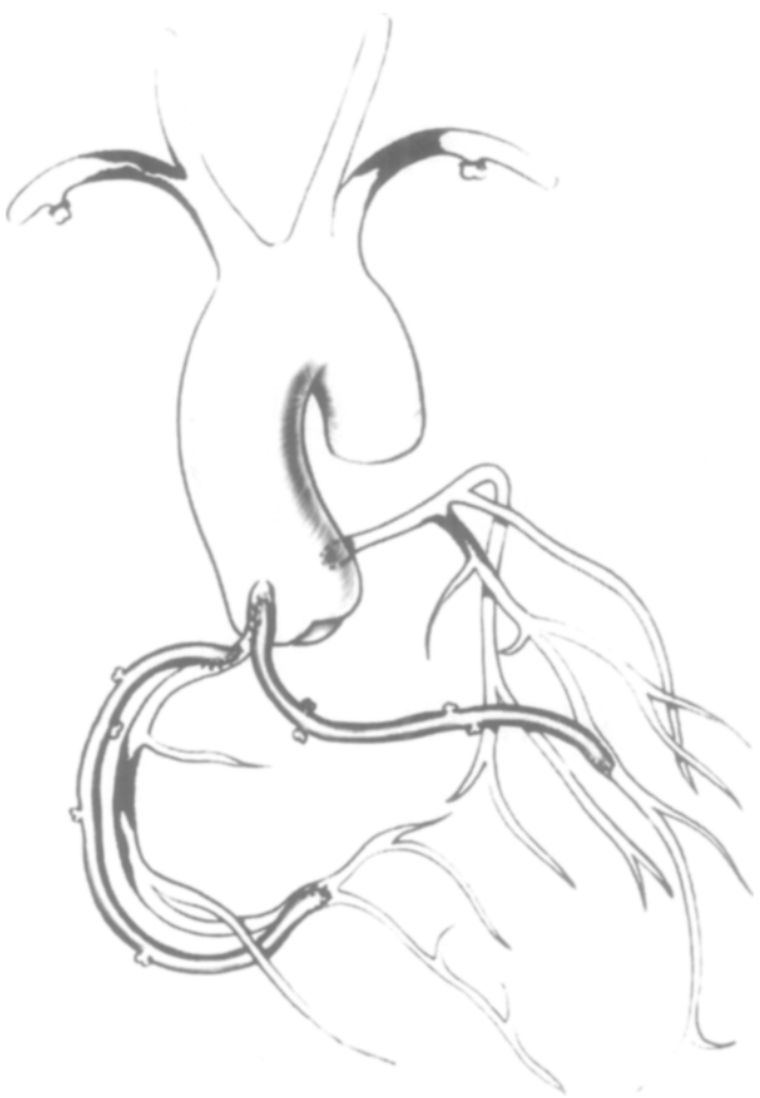

Fig. 5. CCBGs with both ITAs in one case of significant lesions of subclavian arteries. One from RCA to RCA and one from RCA to LAD.

an RCA, except the first centimeters of the artery, to be the preferred situation for CCBG. Subsequently, we have extended CCBG's use in patients with significant stenosis of the RCA. Other sites of proximal implantation are possible ${ }^{4,6}$; proximal implantation on a first diagonal branch has been described elsewhere, ${ }^{6}$ and we have occasionally used the marginal artery and the LAD (in 3.4\% and $2.7 \%$ cases, respectively).

Except in one reported case, ${ }^{4} \mathrm{CCBG}$ was performed either between two segments of the same coronary artery or between its branches, generally the RCA. In our experience, CCBG has been constructed in such a situation in $96.6 \%$ of cases: RCA, 90.5\%; CXA $3.4 \%$; and LAD, $2.7 \%$. We have, however, successfully used the free left ITA in CCBG between RCA and LAD (type of revascularization RCA-left ITA-LAD) in two cases. This type of revascularization was used in one case in which the initial part of the left ITA was injured during harvesting; in the other case, it was used because of 


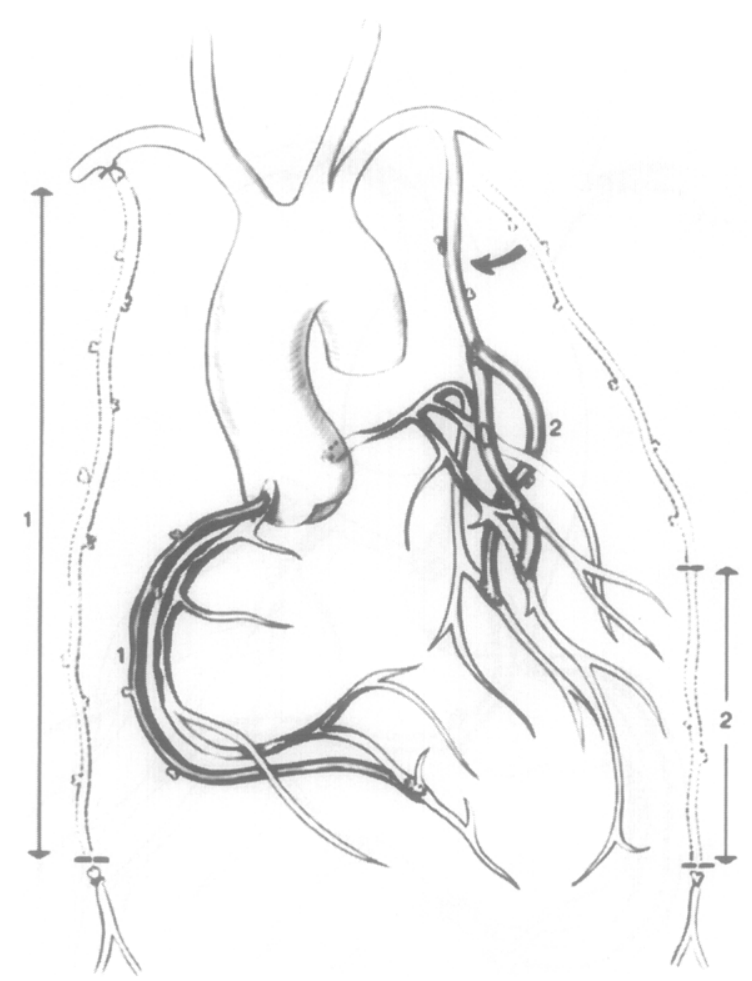

Fig. 6. CCBG with entire right ITA (l) to distal posterior descending artery. Left coronary revascularization with $\mathrm{Y}$ graft using distal part of left ITA (2).

severe atherosclerosis of the proximal left subclavian artery (Fig. 5). In these two cases, CCBG appeared to be an alternative that would avoid aortic implantation of a free left ITA.

Theoretic bases have been advanced to promote the use of this technique, which could from a hemodynamic point of view satisfy the quest for a physiologic restoration of coronary blood flow. ${ }^{3}$ Proximal anastomoses constructed on the coronary artery itself could provide a diastolic blood flow closer to physiologic norms, and the Venturi effect would be limited compared with grafts proximally anastomosed on the ascending aorta, far from the sinuses of Valsalva.

The most critical question concerns the progression of coronary disease at the site of proximal anastomosis. In our series, with a maximum follow-up of 7 years, such progression of disease was never observed. Moreover, a recent study ${ }^{7}$ showed that the most important factor in long-term survival is selection of the conduit, rather than the progression of coronary disease.

Several practical advantages have been found in CCBG. In our opinion, the aim of this technique is to expand the possibility of arterial grafts, in particular the ITA graft, for myocardial revascularization.

This technique has been proposed in cases of severely diseased ascending aorta as an alternative to the previously described procedures with pericardial or Dacron polyester patch replacement of the diseased aorta or graft implantation on the great arch vessels. ${ }^{8,9}$ In fact, CCBG bypass avoids the problems of difficult and unsuitable aortic arterial free graft reimplantation, ${ }^{9}$ which has a late patency in this setting to that of similar saphenous vein grafts. ${ }^{10}$ Proximal anastomoses of arterial free graft in our series were constructed on the coronary artery or on the pedicled ITA graft. CCBGs and Y grafts $^{11,12}$ allowed us to avoid the aortic implantation of arterial free grafts.

Limited lengths of arterial grafts or saphenous veins seem to present a good opportunity to perform CCBG. ${ }^{5,6}$ Inadequate length of the pedicled right ITA to reach the posterolateral myocardial wall limits its use. In these cases, the possibility of excessive tension on the in situ graft or the inconvenience of a free graft implantation on the aorta could compromise potential benefits and would not justify increasing the risk of sternal wound complications encountered with bilateral ITA harvesting. ${ }^{13}$

In an attempt to promote excellent long-term functional results, the current trend is to bypass more coronary arteries with arterial conduits. Although new arterial conduits have been tested, ${ }^{14-18}$ the ITA has become the preferred conduit because of its fundamental characteristics: physiologic adaptability, ${ }^{19,20}$ low vasospastic characteristic, ${ }^{21}$ resistance to atherosclerosis as a result of prostacyclin secretion $^{22}$ and the particularity of the internal elastic lamina, ${ }^{23}$ and harvesting by sternotomy.

To limit the use of other conduits, even in light of the increasing need for multiple coronary revascularizations, we have considered the possibility of extended use of ITA grafts. In addition to sequential anastomosis, which allows revascularization of several coronary vessels with a pedicled ITA graft, ${ }^{24,25}$ CCBG allows us to perform complex myocardial revascularization exclusively with ITAs as an alternative to the other procedures previously described, including three separate arterial conduits. ${ }^{26-28}$ In 62 patients $(43.3 \%)$, the CCBG technique allowed the use of one ITA for two grafts. To decrease the risk of respiratory and sternal morbidity, or to preserve the right ITA for the future, the distal part of the left ITA was used as a CCBG in 11 patients (Fig. 3). To achieve complex three-vessel revascularization with 
both ITAs exclusively, the right ITA was divided to achieve either two CCBGs (three patients) or one CCBG and one Y graft (41 patients). The latter operative procedure with a $\mathrm{Y}$ graft (type of revascularization left ITA-LAD $+Y$ right ITACXA+RCA-right ITA-RCA) has been of special interest (Fig. 2). The posterior and lateral myocardium walls were revascularized by a divided free right ITA and the anterior wall was revascularized by the pedicled left ITA.

CCBG has allowed us to use right ITA in situations in which we otherwise would have been reluctant to do so. CCBG can be used instead of the gastroepiploic artery to revascularize the distal branches of the RCA (Fig. 6). We prefer the CCBG technique when feasible to use of the gastroepiploic artery because the right ITA is a conduit easier to use and less vasospastic. When CCBG is not possible, we often use the gastroepiploic artery for revascularization of the distal branches of the RCA, as described elsewhere. ${ }^{29}$

The aim of this study was not to demonstrate that CCBG was superior to more conventional methods of myocardial revascularization, but to show that CCBG provides an additional alternative technique, with sequential anastomoses and $Y$ grafts, allowing extensive myocardial revascularization with liberal use of both ITAs. In the light of the excellent early patency rates and the good midterm results of this series, we are looking forward to long-term follow-up results.

\section{REFERENCES}

1. Loop FD, Lytle BW, Cosgrove DM, et al. Influence of the internal mammary artery graft on 10-years survival and other cardiac events. N Engl J Med 1986;14:1-6.

2. Effler DB, Favaloro RG, Groves LK. Coronary artery surgery utilizing saphenous vein graft techniques: clinical experience with 224 operations. J Thorac Cardiovasc Surg 1970;59:14753.

3. Biglioli P, Alamanni F, Antona C, Sala A, Susini G. Coronary-coronary bypass: theoretical basis and techniques. J Cardiovasc Surg 1987;28:333-5.

4. Rowland PE, Grooters RK. Coronary-coronary artery bypass: an alternative. Ann Thorac Surg 1987;43:326-8.

5. Nishida H, Soltanzadeh H, Grooters RK, Thieman KC. Coronary-coronary bypass using internal mammary artery. Ann Thorac Surg 1988; 46:577-8.

6. Singh Bedi H, Sharma VK, Kler TS, Trehan N. Coronary-tocoronary bypass using a free internal mammary artery: an alternative. Ann Thorac Surg 1995;59:757-9.

7. Cameron A, Davis KB, Green G, Schaff HV. Coronary bypass surgery with internal thoracic artery graft: effects on survival over a 15 year period. N Engl J Med 1996;334:216-9.

8. Ott DA, Cooley DA. The difficult proximal coronary anastomosis. Cardiovasc Dis Bull Tex Heart Inst 1979;6:55-8.
9. Kanter KR, Barner HB. Improved technique for the proximal anastomosis with free internal mammary artery graft. Ann Thorac Surg 1987;44:556-7.

10. Loop FD, Lytel BW, Cosgrove DM, Golding LAR, Taylor PV, Stewart RW. Free (aorto-coronary) internal mammary artery graft: late results. J Thorac Cardiovasc Surg 1986;92: 827-31.

11. Tector AJ, Amundsen S, Schmahl TM, Kress DC, Peter M. Total revascularization with $\mathbf{T}$ grafts. Ann Thorac Surg 1994:57:33-9.

12. Chocron S, Etievent JP, Schiele F, et al. The Y graft: myocardial revascularization with both internal thoracic arteries. J Thorac Cardiovasc Surg 1994;108:736-40.

13. Kouchoukos NT, Wareing TH, Murphy SF, Pelate C, Marshall WG. Risks of bilateral internal mammary artery bypass grafting. Ann Thorac Surg 1990;49:210-9.

14. Pym J, Brown PM, Charrette EJ, Parker JO, West RO. Gastroepiploic-coronary anastomosis: a viable alternative bypass graft. J Thorac Cardiovasc Surg 1987;94:256-9.

15. Lytle BW, Cosgrove DM, Ratliff NB, Loop FD. Coronary artery bypass grafting with the right gastroepiploic artery. J Thorac Cardiovasc Surg 1989;97:826-31.

16. Puig LB, Ciongolli W, Cividances GV, et al. Inferior epigastric artery as a free graft for myocardial revascularization. J Thorac Cardiovasc Surg 1990;99:251-5.

17. Buche M, Schroeder E, Gurne O, et al. Coronary artery bypass grafting with an inferior epigastric artery: midterm clinical and angiopraphic results. J Thorac Cardiovasc Surg 1995; 109:553-60.

18. Acar C, Jebara VA, Portoghese M, et al. Revival of the radial artery for coronary artery bypass grafting. Ann Thorac Surg 1992;54:652-60.

19. Singh RN, Beg RA, Kay EB. Physiological adaptability: the secret of success of the internal mammary artery grafts. Ann Thorac Surg 1986;41:247-50.

20. Aris A, Borras X, Ramio J. Patency of internal mammary artery grafts in no-flow situations. J Cardiovasc Surg 1987;93: 62-4.

21. Yang $Z$, Diederich $D$, Scheinder $K$, et al. Endotheliumderived relaxing factor and protection against contractions induced by histamine and serotonin in the human internal mammary artery and the saphenous vein. Circulation 1989; 80:1041-8.

22. Chaikhounia A, Crawford FA, Kochel PJ, Olanoff LS, Halushka PV. Human internal mammary artery produces more prostacyclin than saphenous vein. J Thorac Cardiovasc Surg 1986;92:88-91.

23. Van Son JA, Smedts F, Vincent JG, Van Lier HJ, Kubat K. Comparative anatomic studies of various arterial conduits for myocardial revascularization. J Thorac Cardiovasc Surg 1990; 99:703-7.

24. Kieser TM, Fitz Gibbon GM, Keon WJ. Sequential coronary bypass grafts. J Thorac Cardiovasc Surg 1986;91:767-72.

25. Dion R, Verhelst R, Rousseau M, Goenen M, Ponlot R, Kestens-Servaye $\mathrm{Y}$, et al. Sequential mammary grafting. J Thorac Cardiovase Surg 1989;98:80-9.

26. Buche M, Schoevaerdts JC, Chalant CH. Multiple-vessel coronary revascularization using both in situ mammary arteries and a free inferior epigastric artery. J Thorac Cardiovasc Surg 1990;99:754-5.

27. Jegaden O, Eker A, Montagna P, et al. Risk and results of 
bypass grafting using bilateral internal mammary and right gastroepiploic arteries. Ann Thorac Surg 1995;59:955-60.

28. Calafiore AM, Di Giammarco G, Luciani N, Maddestrà N, Di Nardo E, Angelini R. Composite arterial conduits for a wider arterial myocardial revascularization. Ann Thorac Surg 1994;58:185-90.

29. Mills NL, Hockmuth DR, Everson CT, Robert CC. Right gastroepiploic artery used for coronary artery bypass grafting: evaluation of flow characteristics and size. J Thorac Cardiovasc Surg 1993;106:579-86.

\section{Discussion}

Dr. Noel L. Mills (New Orleans, La.). There are a couple of points that I would like to address first. I noted that you wrapped the ITA grafts with a dipyridamolesoaked sponge. Is there any preference for this in the literature, or have you determined that this drug externally does dilate the ITA? Second, you the noted that three patients died on the first postoperative day. Were these three arterial grafts open at postmortem?

You have chosen a CCBG for the purpose of sparing arterial conduit. I question your liberal use of this operation. In 6 years you found 143 patients in whom to perform this procedure, which is $11.3 \%$ of patients operated on in your institution for myocardial revascularization. In the past, this operation has been used when one really has one's back against the wall, seeking out conduit when there is very little available. Of the 134 patients who had the RCA as the origin of the graft, 112 had the grafts put in proximal to the posterior descending. are ignoring the pathology of atherosclerosis, which is an ongoing disease. The origin of the posterior descending is a primary point where atherosclerosis progresses. Likewise, the RCA itself has a tremendous propensity toward the progression of coronary artery disease over the years. Therefore these right system grafts are in double jeopardy from two points. The mean postoperative follow-up was just under 3 years, which is not long when one considers that the average age of the patients was 63 years.

Some of the statistics from this report are worth mentioning. For one, $4.8 \%$ of the patients had to be ventilated for longer than 2 days. Only $3.5 \%$ of the patients had respiratory disease, and you do not state whether prolonged ventilation was secondary to the operative technique, emergency operation, or obesity. In any event, postoperative ventilator support is costly, and $5 \%$ ventilated longer than 2 days is higher than one would expect in these days of fast-tracking.

The cardiopulmonary bypass time was an average of 2 hours and 10 minutes in this group of patients who had only a mean of three distal anastomoses. This is a longer pump run than most of us would see in patients with three distal anastomoses, and we need know to know whether this prolonged pump time is inherently due to the operation itself. The mean aortic crossclamp time was almost $1 \frac{1 / 2}{2}$ hours for this average of three distal anastomoses.

I think we have to be careful; there have been some technical gymnastics in coronary artery bypass surgery that have proved disastrous. Just because an operation can be done does not mean that it should be done, except perhaps in unusual circumstances. Because only four patients of 143 were undergoing a reoperation, I feel certain that adequate conduit was available in by far the majority of this group of patients.

I looked up some postoperative follow-up angiograms of 15 patients operated on 10 years earlier for this review and found that the right coronary disease had progressed to the ostia in almost $50 \%$. This needs to be looked at in a more formal study before we can recommend this operation for any extended use.

I think you have made a contribution in showing us that this indeed is a good trick.

Dr. Nottin. Regarding the use of papaverine and dipyridamole solution, Dion and colleagues ${ }^{17}$ reported good results with this type of solution. We consider, however, that the injection of solution into the graft might induce lesions of the endothelium. Also, we harvest the ITA as skeletonized. This allows excellent flow without any spasm.

All of the three early deaths were related to myocardial infarction, not to a failure of CCBG. One patient had a saphenous CCBG on the RCA; the two others had CCBGs on the RCA performed with a free segment of the left ITA.

Site of distal implantation of right CCBG was always determined by precise analysis of the most distal stenosis. In our series, 107 patients had right CCBG proximal to or at the bifurcation of the RCA. This clearly means that in these cases no critical stenoses were noted distally. In cases of stenosis of the posterior descending artery or any distal branches of the RCA, we always performed distal bypass either as single bypass ( 23 patients) or as sequential bypass (four patients with multiple lesions on branches of the RCA). Considering that atherosclerosis may be an ongoing disease, this phenomen is unpredictible and is obviously not specific to CCBG.

Seven patients had prolonged ventilatory support. That represents about $5 \%$, including four patients with severe chronic obstructive pulmonary disease, two patients with low cardiac output, and one with bleeding.

Mean aortic crossclamp time was 83 minutes for 3.2 distal anastomoses, but this time included also proximal anastomoses of CCBG (1 anastomosis per patient) and proximal anastomoses of $Y$ grafts ( $65 / 143$ patients, an average of 0.45 anastomoses per patient). If we calculate the total number of anastomoses performed under aortic crossclamping, we arrive at 4.7 per patient. The duration of cardiopulmonary bypass was related to a weaning protocol that included half the time of aortic crossclamping before discontinuation of cardiopulmonary bypass.

The most critical question concerns the risk of progression of the coronary disease at the site of proximal anastomosis. In our series, with its maximum follow-up of 7 years, such progression of disease has not been observed; however, only 20 patients have undergone late angiography. Moreover, recent studies have demonstrate that the most important factor in long-term results is the selection of the conduit, rather than the progression of the coronary disease. We can also easily imagine that atherosclerosis of the origin of the RCA will not progress proximal to a CCBG for obvious hemodynamic reasons.

We hope that long-term results, particularly patency of grafts and absence of progression of atherosclerosis on late angiography, will demonstrate that $\mathrm{CCBG}$ is a good alternative technique. 